deriving an average respectively of $44 \%$ and $32 \%$ of calories from fat. Furthermore, although careful steps were taken to validate the dietary questionnaire, the inevitable imprecision of data derived from questionnaires was evident from the information provided.

The best evidence of any causal association would be provided by an intervention study. The United States National Cancer Institute will shortly decide whether to proceed with a large randomised trial to test the hypothesis that restricting dietary fat can reduce the incidence of breast cancer. ${ }^{27}$ The trial would include 32000 women aged 45 to 69 with risk factors for breast cancer. A pilot study has shown that a substantial reduction in fat intake (from an average of $39 \%$ of calories to $21 \%$ ) can be achieved and sustained for at least one year. Critics of the proposed trial, which would last a decade and cost around $\$ 100 \mathrm{~m}$, argue that the resources might be spent more effectively on observational studies or laboratory research. But the organisers believe that this may be the only way to settle the long standing debate about fat and breast cancer.

Professor of Preventive and Social Medicine and

D C G SKEGG

Director of the Hugh Adam Cancer Epidemiology Unit,

University of Otago,

Dunedin, New Zealand

1 Peto R. The preventability of cancer. In: Vessey MP, Gray M, eds. Cancer risks and prevention. Oxford: Oxford University Press, 1985:1-14.

Byers T, Graham S, Rzepka T, Marshall J. Lactation and breast cancer. Am $\mathcal{J}$ Epidemiol 1985;121:664-74.

3 Trichopoulos D, Hsieh C, MacMahon B, et al. Age at any birth and breast cancer risk. Int f Cancer 1983;31:701-4.

4 Baron JA. Smoking and estrogen-related disease. Am f Epidemiol 1984;119:9-22.
5 Baron JA, Byers T, Greenberg ER, Cummings KM, Swanson M. Cigarette smoking in women with cancers of the breast and reproductive organs. $\mathcal{F}$ Natl Cancer Inst 1986;77:677-80.

6 O'Connell DL, Hulka BS, Chambless LE, Wilkinson WE, Deubner DC. Cigarette smoking, lcohol consumption, and breast cancer risk. $\mathcal{F}$ Natl Cancer Inst 1987;78:229-34.

7 Lubin F, Ruder AM, Wax Y, Modan B. Overweight and changes in weight throughout adult life $C$ in breast cancer etiology. Am $\mathcal{F}$ Epidemiol 1985;122:579-88.

8 Willett WC, Browne ML, Bain C, et al. Relative weight and risk of breast cancer among

Williams RR, Horm JW. Association of cancer sites with tobacco and alcohol consumption and 70 socioeconomic status of patients: interview study from the Third National Cancer Survey. \& 7 Natl Cancer Inst 1977;58:525-47.

10 Graham S. Alcohol and breast cancer. N Engl F Med 1987:316:1211-3.

11 Harvey EB, Schairer C, Brinton LA, Hoover RN, Fraumeni JF. Alcohol consumption and breast 2 cancer. $\mathcal{F}$ Natl Cancer Inst 1987;78:657-61.

12 Hiatt RA, Bawol RD. Alcoholic beverage consumption and breast cancer incidence. Am $\mathcal{F}$ Epidemiol 1984;120:676-83.

13 Schatzkin A, Jones DY, Hoover RN, et al. Alcohol consumption and breast cancer in the epidemiologic follow-up study of the first National Health and Nutrition Examination Survey. N Engl f Med 1987;316:1169-73.

14 Willett WC, Stampfer MJ, Colditz GA, Rosner BA, Hennekens CH, Speizer FE. Moderate alcohol consumption and the risk of breast cancer. $N$ Engl F Med 1987;316:1174-80.

15 Minton JP, Foecking MK, Webster DJT, Matthews RH. Caffeine, cyclic nucleotides, and breast disease. Surgery 1979;86:105-8.

16 Lubin F, Ron E, Wax Y, Modan B. Coffee and methylxanthines and breast cancer: a case-control study. F Natl Cancer Inst 1985;74:569-73.

17 Rosenberg L, Miller DR, Helmrich SP, et al. Breast cancer and the consumption of coffee. $A m \mathcal{J}$ Epidemiol 1985;122:391-9.

18 La Vecchia C, Talamini R, Decarli A, Franceschi S, Parazzini F, Tognoni G. Coffee consumption and the risk of breast cancer. Surgery 1986;100:477-81.

19 National Research Council. Diet, nutrition, and cancer. Washington, DC: National Academy Press, 1982:83-6.

20 Gray GE, Pike MC, Henderson BE. Breast-cancer incidence and mortality rates in different countries in relation to known risk factors and dietary practices. $\mathrm{Br} \mathcal{F}$ Cancer 1979;39:1-7.

21 Hirayama T. Diet and cancer. Nutr Cancer 1979;1:67-81.

22 Armstrong BK, Mann JI. Diet. In: Vessey MP, Gray M, eds. Cancer risks and prevention. Oxford: Oxford University Press, 1985:68-98.

23 Lubin F, Wax Y, Modan B. Role of fat, animal protein, and dietary fiber in breast cancer etiology: a case-control study. I Natl Cancer Inst 1986;77:605-12.

24 Hirohata T, Nomura AMY, Hankin JH, Kolonel LN, Lee J. An epidemiologic study on the association between diet and breast cancer. $\mathcal{F}$ Natl Cancer Inst 1987;78:595-600.

25 Katsouyanni K, Trichopoulos D, Boyle P, et al. Diet and breast cancer: a case-control study in $\mathrm{O}$ Greece. Int f Cancer 1986;38:815-20.

26 Willett WC, Stampfer MJ, Colditz GA, Rosner BA, Hennekens CH, Speizer FE. Dietary fat and $N$ the risk of breast cancer. $N$ Engl $\mathcal{F}$ Med 1987;316:22-8.

27 Women's Health Trial Steering Committee. The Women's Health Trial: a randomized trial to prevent breast cancer incidence with a low fat diet. Abstracts for the International Epidemiological Association, XI Scientific Meeting. Helsinki: International Epidemiological Association, 1987:262-3.

4. Bas

\title{
Spending more on turning patients into people
}

In her 17 articles on rehabilitation published in the $B M \mathcal{F}$ in 1985 Daphne Gloag defined “disability” as a restriction or lack of ability in normal activities resulting from an impairment, and "handicap" as the resulting social disadvantage." She also quoted the relative of a severely disabled person who defined rehabilitation as "restoration from patient to person." Ms Gloag's articles followed many other reports on rehabilitation, including a BMA report of $1954^{2}$ and the Tunbridge and Mair $^{4}$ reports of 1972. These reports recognised that consultants, general practitioners, and members of the community services would each have some responsibility for rehabilitation but said that specialist facilities would also be necessary. The Tunbridge report deplored the lack of interest in rehabilitation among doctors and other health workers, and this lack of interest is still all too common in 1987 despite considerable growth in public and professional awareness of the importance of rehabilitation.

In 1985 there were only 23 senior registrar posts in the United Kingdom giving training in rehabilitation with the ultimate potential of accreditation in the specialty, and 18 of these were linked to rheumatology. The report of the Royal College of Physicians of London, Physical Disability in 1986 and Beyond ${ }^{5}$ paid tribute to the many voluntary organisations in Britain that have contributed to caring for disabled people and listed the many agencies and disabled living centres where advice and help can be obtained. But that report, like the many which preceded it, drew attention to the serious inadequacy of hospital based services and to their uneven distribution throughout Britain. It recommended that each regional health authority should set up a regional disability medicine subcommittee; it also advocated establishing regional disability units staffed by the equivalent of two full time consultants.

As a neurologist I can testify to the uneven distribution of resources in Britain. In the region in which I now work there are, to quote a few examples, the world famous Spinal Injuries Centre at Stoke Mandeville, the equally notable Mary Marlborough Lodge at the Nuffield Orthopaedic $\mathcal{N}$ Centre, Ritchie Russell House for the care of patients with $\frac{7}{0}$ multiple sclerosis and other chronic neurological disorders, and the admirable Rivermead Rehabilitation Centre; and a consultant in neurological rehabilitation has recently been $\underset{\omega}{\omega}$ appointed. But in my former region facilities were much 2

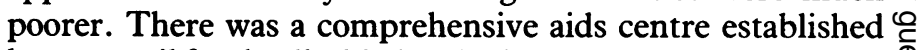
by a council for the disabled and other scattered facilities, but $\stackrel{\oplus}{\stackrel{\oplus}{\rightarrow}}$ attempts by neurologists and neurosurgeons over more than 25 years to persuade the authorities to establish a regional rehabilitation centre had failed.

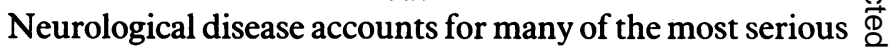
physically disabling disorders: stroke, head injury, epilepsy, multiple sclerosis, Parkinson's disease, motor neurone 8 disease, and the other neuromuscular disorders such as muscular dystrophy are important examples. And the press- 흘




mental disease or handicap, or both, are well recognised. Recent surveys undertaken by the Association of British Neurologists have shown that the existing burden of clinical work and responsibility shouldered by clinical neurologists in Britain is such as to demand an urgent increase in the consultant establishment. We can but hope that Achieving a Balance will start this process. The council of the association recently confirmed that neurologists are willing to play an increasing part in managing neurological disability, but this will be possible only when existing clinical pressures are relieved.

The advice which doctors and health authorities have received from innumerable authoritative sources over more than 30 years is unequivocal and clear. We have heard about the Cinderella specialties, and rehabilitation is plainly one. Resources are finite and rapid expansion may be impracticable, but a rapid ascent for this specialty in the priority stakes is clearly justified-and neurologists are prepared to participate fully. And surely all health authorities should urgently re-examine the rehabilitation facilities they now provide and correct the most glaring deficiencies.

\section{SIR JOHN WALTON}

\section{President,}

Association of British Neurologists,

Green College,

Oxford OX2 6HG

1 Gloag D. Needs and opportunities in rehabilitation. BrMed $\mathcal{f}_{1985 ; 290: 43,132,220,301,368,455}$ $542,617,699,768,834,913,981,1059,1135,1201,1333$.

2 British Medical Association. The rehabilization and resettlement of disabled persons. London: BMA 1954.

3 Department of Health and Social Security, Central Health Services Council. Rehabilitation London: HMSO, 1972.

4 Scottish Home and Health Department, Scottish Health Services Council. Medical rehabilitation Edinburgh: HMSO, 1972

5 Royal College of Physicians of London. Physical disability in 1986 and beyond. $\mathcal{f} R$ Coll Physician Lond 1986;20:160-94.

\section{Smallpox ten years gone: what next?}

Ten years ago this week in Merka, Somalia, the last naturally occurring case of smallpox in the world was reported. This was the first and only time that a positive attempt to eradicate an infection had succeeded. What are the prospects for eradicating other diseases?

Eradication is "the extinction of the pathogen that causes the infectious disease in question." In elimination the disease disappears but the causative agent remains. The characteristics of an infection that may make it eradicable are its limitation to humans, an easily recognisable illness with no subclinical or latent infection, no long term carriers, lifelong immunity with visible evidence of immunity, low to moderate infectivity, a medium to long incubation period, ${ }^{2}$ and, of course, the availability of an effective tool for interrupting transmission. Smallpox had all these characteristics.

The six target diseases of the World Health Organisation's expanded programme on immunisation are measles, pertussis, neonatal tetanus, polio, tuberculosis, and diphtheria. ${ }^{3}$ Many of the factors necessary for elimination are present for each of these diseases-but some are not. Measles immunity is not easily recognisable, and the infection is so highly communicable that a vaccine efficacy rate of about $95 \%$ is probably not high enough even to eliminate, much less eradicate, the disease. ${ }^{4}$ An outbreak of measles recently occurred in a secondary school in the United States, although more than $99 \%$ of the students were vaccinated and $95 \%$ had serological immunity. ${ }^{5}$ Pertussis is also highly infectious, immunity is not recognisable, and the vaccine is almost certainly not effective enough and in any case probably does not prevent carriage of the organism. As Clostridium tetani is ubiquitous tetanus is not eradicable. Neonatal tetanus could theoretically be eliminated in the Third World if $100 \%$ of pregnant women were vaccinated, but in practice combining immunisation and health education should prove more effective.

Most infection with poliovirus is subclinical, and immunity is clinically unrecognisable. But countries that are efficient at giving vaccines have proved remarkably successful not only in practically eliminating the disease but also in virtually eradicating the organism; the Pan American Health Organ- isation aims at eradicating polio from the Americas by $1990 .{ }^{6}$ Nevertheless, the widespread use of the live vaccine has led to the circulating wild virus being replaced by the vaccine virus, ${ }^{7}$ which has some neurological side effects of its own. Tuberculosis is clearly not eradicable at present, and, although little of the decreasing incidence and severity of the disease of the last century can be attributed to medical planning, much can still be done to further reduce its incidence.

Diphtheria has many features that suggest that it cannot easily be eradicated, especially as in theory the vaccine should not affect the carrier state. Nevertheless, with a national immunisation rate in Britain of $84 \%$ not only are cases of diphtheria rare but so also are isolations of toxigenic strains. Such cases and strains are occasionally reported, however, and serological studies and localised outbreaks in countries with high immunisation rates ${ }^{89}$ suggest that we cannot be complacent.

Prospects for eradicating congenital rubella syndrome are more encouraging. Cases reported each year in the United States have declined steadily: only two cases were reported in 1984 and $1985 . .^{10}$ Although the syndrome is notoriously undernotified and underdiagnosed, reduction has been achieved by universal immunisation augmented by selective immunisation of adult women of childbearing age; recently announced changes in British policy are intended to eliminate rubella and the congenital rubella syndrome although prospects for eradicating the virus are remote.

The case for eliminating mumps on grounds of cost benefit is not strong, ${ }^{11}$ but it strengthens when mumps vaccine is given with measles and rubella. The prospects for elimination or eradication are probably similar to those for rubella; a vaccine coverage rate of $85 \%$ at the age of 2 years is said to be adequate. ${ }^{12}$ With all these diseases there are epidemiological side effects of mass immunisation, ${ }^{4}$ which are mainly those of altering the age distribution of the disease. ${ }^{513}$

Clearly we cannot be wildly optimistic about eradicating many infections with vaccines in the near future, but strategies other than immunisation are available. The universal provision of safe drinking water will eradicate diseases transmitted solely by this route-for example, 